\title{
Risk Factors and Behaviours of Schoolchildren with Myopia in Taiwan
}

Han-Chih Cheng, $\mathrm{MD}^{1,2}$, Koyin Chang, $\mathrm{PhD}^{3}$, Elizabeth P. Shen, MD, PhD ${ }^{1,2}$ KaiShin Luo, MD ${ }^{1}$, Yung-hsiang Ying, $\mathrm{PhD}^{4 *}$

1 Department of Ophthalmology, Taipei Tzu-chi Hospital

2 Department of Ophthalmology, Tzu Chi University

3 Department of Healthcare Information and Management, Ming Chuan University

4 College of Management, National Taiwan Normal University

Correspondence: Yung-hsiang Ying, PhD.*

College of Management, National Taiwan Normal University

Address: No. 162, Sec. 1, He-Ping E. Rd., Taipei 10610, Taiwan (R.O.C)

Tel: 886-2-7734-1018

Email: yying@ntnu.edu.tw

The authors have no conflict of interests.

Funding sources: Taipei Tzu Chi Hospital, Buddhist Tzu Chi Medical Foundation, New Taipei, Taiwan (TCRD-TPE-108-47) 


\begin{abstract}
Importance: Because of the high prevalence of myopia in Taiwan, understanding the risk factors for its development and progression is important to public health.

Background: This study investigated the risk factors for myopia and their influence on the progression of myopia in schoolchildren in Taiwan.

Design: Patients' clinical records were obtained retrospectively from ophthalmologists. Questionnaires were given to collect demographic information, family background, hours spent on daily activities, myopia progression, and treatment methods.
\end{abstract}

Participants: A total of 522 schoolchildren with myopia from a regional medical hospital in northern Taiwan participated the study. Written informed consent was obtained from the participants of legal age or the parents or legal guardians.

Methods: Multivariable regression analyses were performed. Myopia measured in dioptres was analysed, controlling for patients' family and demographic information as well as their daily behaviours.

Main Outcome Results: Children with high myopic parents were more myopic.

Earlier onset age of myopia was associated with a higher level of myopia and greater annual myopic progression. Children reporting more near work activities had higher levels of myopia and greater progression of myopia. Lower levels of myopia were associated with more exercise, longer periods of sleep, and better vision care knowledge in children and parents. Intake of food supplements had no effect on myopia.

Conclusions and Relevance: In addition to genetics, education, environment, and near work activity can influence the development of myopia. Health policies for schoolchildren should promote protective activities and vision care knowledge in order to protect the eyesight of schoolchildren.

Keywords: Myopia progression, environmental factors, vision care knowledge 


\section{Introduction}

Myopia is a highly prevalent disease throughout the world. High myopia is often associated with vision debilitating diseases such as cataract, glaucoma, maculopathy, and retinal detachment $[1,2,3]$. Myopia-associated maculopathy has been reported as a leading cause of irreversible blindness in many countries $[4,5,6,7,8,9]$. Previous research determined that controlling myopic progression in children could lower the relative risk of development of myopic maculopathy, retinal detachment, and posterior subcapsular cataract by about 5 times, 3 times, and 1.5 times, respectively $\left[{ }^{10}\right]$. Therefore, screening for myopic children and preventing or reducing myopic progression is of paramount importance to protecting and promoting public health. About 30 years ago, the Taiwan Ministry of Education (MOE) initiated the Taiwan Student Vision Care Program (TSVCP) to combat myopia. Nationwide, school nurses conduct regular vision testing in elementary school students every semester. Students with vision below 20/25 are required to visit an ophthalmologist for further evaluation $\left[{ }^{11}\right]$. This national screening program has resulted in approximately $80 \%$ of schoolchildren in Taiwan being seen by ophthalmologists for further eye care and intervention for myopia progression control. Despite these efforts, myopia prevalence in Taiwanese schoolchildren did not decrease significantly. Therefore, understanding the possible environmental and lifestyle factors that may contribute to myopia progression is of paramount importance in promoting the ocular health of these children. In this study, we investigated the environmental and lifestyle factors associated with myopia progression in schoolchildren regularly followed at our outpatient clinic in a regional medical hospital in Northern Taiwan. The result of this 
study may identify the potential risks factors for myopia, influencing future health policies for vision care among children.

\section{Methods}

\section{Study Design and Patient Population}

To understand the risk factors for progression of myopia and the influence of each, a specially designed survey of schoolchildren's family background and daily activities was conducted. The questionnaire combined patient characteristics and behaviour with clinical information. The study targeted those who, at the time of our study, were either referred to ophthalmologists' offices after failing the school vision screening or were returning myopia patients of the ophthalmologists. Only schoolchildren aged 620 years were included in the study. The data collection period was from February 2018 to November 2018. All the patients were referred to the interviewers by their ophthalmologist after full explanation of the purpose of the study and obtaining written informed consent from the participants (if of legal age) or their parents or guardians. This study was carried out according to the tenets of the Declaration of Helsinki and the Research Governance Framework for Health and Social Care. The questionnaire was completed by parents / guardians and schoolchildren together or by the children themselves if they were old enough to read the questions. This study was approved by the Institutional Review Board of Taipei Tzu-Chi Hospital (identifier, 06-X22-086).

Of the 603 patients invited to take part, 522 completely answered all the questions. The inclusion criteria for our subjects were: (i) outpatients with myopia or pseudomyopia; (ii) speakers of Chinese or Taiwanese; (iii) age between 6 and 20 
years; (iv) ability of parents / guardians to provide informed consent; and (v) lack of other serious eye diseases.

\section{Ethics, Governance, and Consent}

Clinical data were obtained from patients' ophthalmologists regarding their dioptres, myopia progress since the last annual visit, and treatment. To include appropriate questions in the survey, the potential risk factors that contribute to myopia were drawn from a systematic review of the relevant literature.

\section{Outcome Measures}

Two types of outcome measures were obtained. First, the degree of myopia was measured in dioptres for both eyes. Secondly, the progress of myopia was measured by calculating the increase in schoolchildren's dioptres in the past year.

\section{Risk Factors}

The myopia risk factors were obtained from the recent literature $[12,13,14,15,16]$. Shih et al. reported the effectiveness of atropine on myopia progression in Taiwanese schoolchildren $\left[{ }^{17}\right]$. Thus, whether or not the myopia was treated with long-acting mydriatics (i.e., atropine) was considered as an influential factor. Genetics has long been linked directly to myopia. Thus, parents' myopia or not was included as an effective measure of the genetic factor. Daily activities such as hours spent on exercise, sleep, study (near work activity), TV watching, usage of electronic devices with an illuminated screen, and hours spent in "cram school" (confined environment) after regular school hours may potentially affect children's vision. Family background information such as living space, income level, and parents' knowledge about vision 
care were controlled for in the analyses. Clinical information included presence of other eye problems such as amblyopia or heterotropia, intake of food supplements, academic achievement measured by school grade, height, weight, age of onset of myopia, frequency of office visits, and the use of vision corrective tools.

\section{Vision Care Knowledge}

Schoolchildren's vision can be better cared for if parents have the relevant vision care education. Ten questions, designed in a 5-point Likert scale, were used to ascertain the eye care knowledge of the parents / guardians (or the students if of legal age). A score of five on the Likert scale meant strongly agree and 1 meant strongly disagree. The questions were as follows.

a. Long-acting mydriatic agent is harmful to eyes.

b. Long-acting mydriatic agent is proven to be effective in controlling myopia.

c. Vision deteriorates faster for people with myopic squinting and seeing without appropriate corrective lenses

d. It is better not to wear eyeglasses even when you have myopia since eyeglasses may very likely make your vision worse.

e. Pupil dilating effect will disappear once you stop using mydriatic agents.

f. Corrective lens power should be less than your real power since the full correction lenses may accelerate myopia progression.

g. Usage of electronic devices will accelerate myopia progression.

h. Eye health and vision can be improved by adequate outdoor activities and exercise.

i. “30/10 Rule" refers to every 30 minutes spent in near work activity requires a 10minute rest.

j. High myopia is nothing to worry. It is not associated with retinal problems, 
glaucoma, cataract, or any other eye diseases.

For the above ten questions, a higher number in the Likert scale meant better knowledge except for the four questions that were reverse-scored (a, d, f, and j). Based on the answers, each respondent received a knowledge index score from 1 to 100, with higher scores indicating a greater level of vision care knowledge.

\section{Sampling}

Myopia is a common eye problem in Taiwan. Since the Taiwan MOE and Ministry of Health and Welfare have collectively implemented an eye care program in all level of schools and the vision impairment referral rate has achieved $80 \%$, it is reasonable to believe that outpatient services for myopia cover a representative range of schoolchildren with myopia. The patients surveyed were from Tzu-Chi Hospital, Taipei Branch, which is a regional medical hospital in northern Taipei.

\section{Multivariate Regression Analysis}

The ordinary least square (OLS) method was employed to explain the variation in degree of schoolchildren's nearsightedness. Dioptre for each child was obtained. The progression of nearsightedness in the past year was also transcribed from the children's medical record to gain an understanding of the extent to which each risk factor contributed to the progression of myopia. Various functional forms of OLS estimates were explored to find a good model of fit, including linear, natural log, and quadratic forms.

\section{Results}

Patient Demographics 
Table 1 provides the descriptive analysis of schoolchildren's demographic information, including age, gender, family income, and the distribution of degree of myopia. Of all sampled schoolchildren, the average age ( \pm standard deviation) was $11.31( \pm 3.08)$ years; boys comprised $49.81 \%$ of the schoolchildren with myopia. On average, participants had a follow-up visit to the ophthalmologist office every 4.17 $( \pm 1.80)$ months. Approximately $22.56 \%$ of the sampled patients went to private school, which is considered to be more demanding in terms of academic work. A total of $62.45 \%$ of the sampled schoolchildren also attended an independent private class after school for test preparation or extended learning, or so-called "cram schools" in Taiwan. Their daily activities included an average daily habit of using electronic devices, TV watching, studying, and exercise of 1.94, 1.77, 3.08, 3.68 hours, respectively. The average age of myopia onset was 8.24 years. Columns (2) to (4) present the results by educational stages. The progression of myopia within the past year was most severe for primary schoolchildren and mildest for high school students.

Table 1. Subject Demographic Information.

\begin{tabular}{|c|c|c|c|c|}
\hline & Total & Primary & Middle & High School \\
\hline Number & 522 & 344 & 115 & 63 \\
\hline Age (years) & $\begin{array}{l}11.31 \\
(3.08)\end{array}$ & $\begin{array}{c}9.58 \\
(1.91)\end{array}$ & $\begin{array}{l}13.55 \\
(1.21)\end{array}$ & $\begin{array}{l}16.60 \\
(1.32)\end{array}$ \\
\hline Male & $49.81 \%$ & $53.20 \%$ & $45.22 \%$ & $39.68 \%$ \\
\hline $\mathbf{B M I}^{\dagger}$ & $\begin{array}{l}18.63 \\
(4.02)\end{array}$ & $\begin{array}{l}17.57 \\
(3.48)\end{array}$ & $\begin{array}{l}20.08 \\
(4.01)\end{array}$ & $\begin{array}{l}21.89 \\
(4.31)\end{array}$ \\
\hline $\begin{array}{l}\text { Frequency } \\
\text { (months) }\end{array}$ & $\begin{array}{c}4.17 \\
(1.80)\end{array}$ & $\begin{array}{c}3.92 \\
(1.80)\end{array}$ & $\begin{array}{c}4.62 \\
(1.65)\end{array}$ & $\begin{array}{c}4.76 \\
(1.87)\end{array}$ \\
\hline Private School & $22.56 \%$ & $19.82 \%$ & 23.00 & $36.51 \%$ \\
\hline Cram School & $62.45 \%$ & $64.50 \%$ & $66.37 \%$ & $44.44 \%$ \\
\hline \multicolumn{5}{|l|}{ Activity Hours } \\
\hline Cram School & $\begin{array}{c}1.98 \\
(1.97) \\
\end{array}$ & $\begin{array}{c}2.17 \\
(2.06) \\
\end{array}$ & $\begin{array}{c}1.81 \\
(1.83) \\
\end{array}$ & $\begin{array}{c}1.11 \\
(1.49)\end{array}$ \\
\hline Electronic Devises & $\begin{array}{c}1.94 \\
(1.43) \\
\end{array}$ & $\begin{array}{c}1.54 \\
(1.26)\end{array}$ & $\begin{array}{c}2.30 \\
(1.36)\end{array}$ & $\begin{array}{c}3.43 \\
(1.27)\end{array}$ \\
\hline TV & 1.77 & 1.83 & 1.63 & 1.71 \\
\hline
\end{tabular}




\begin{tabular}{ccccc}
\hline & $(1.16)$ & $(1.10)$ & $(1.15)$ & $(1.41)$ \\
\hline Study & 3.08 & 2.93 & 3.26 & 3.50 \\
& $(1.10)$ & $(0.97)$ & $(1.21)$ & $(1.24)$ \\
\hline Sleep & 7.66 & 7.90 & 7.29 & 7.00 \\
& $(1.12)$ & $(1.11)$ & $(0.95)$ & $(0.96)$ \\
\hline Exercise & 3.68 & 3.80 & 3.65 & 3.16 \\
& $(3.42)$ & $(3.19)$ & $(4.15)$ & $(3.19)$ \\
\hline Dioptre & & & & \\
\hline Worsening & 242.80 & 195.04 & 320.25 & 362.17 \\
(in past year) & $(213.16)$ & $(183.76)$ & $(223.91)$ & $(254.13)$ \\
\hline Knowledge & 50.54 & 53.24 & 47.82 & 42.7 \\
& 76.52 & 77.18 & 75.00 & 75.67 \\
\hline Onset Age & $(10.22)$ & $(9.96)$ & $(10.51)$ & $(10.92)$ \\
\hline Other Eye Disorders & 8.24 & 7.46 & 9.46 & 10.36 \\
\hline Amblyopia & $9.41 \%$ & $9.55 \%$ & $8.03 \%$ & $11.11 \%$ \\
\hline Strabismus & $5.69 \%$ & $6.27 \%$ & $5.36 \%$ & $3.17 \%$ \\
\hline
\end{tabular}

Numbers in parentheses represent \pm standard deviation.

${ }^{\dagger}$ Body Mass Index (BMI) is calculated as body mass (in $\mathrm{kg}$ ) divided by the square of body height (in $\mathrm{m}$ ) or $\mathrm{kg} / \mathrm{m}^{2}$.

Negative signs of dioptres for myopia are omitted.

Table 2 presents schoolchildren's intake of food supplements and treatment for myopia. Common eye care supplements in Taiwan include vitamins, fish oil, and lutein, with the percentage of intake among schoolchildren of $15.32 \%, 9.34 \%$, and $13.98 \%$, respectively. Fully $97.31 \%$ of schoolchildren use a mydriatic, with $28.8 \%$ using a long-acting mydriatic agent such as atropine.

Table 2. Intake of Food Supplements for Eye Care and Treatment for Myopia.

\begin{tabular}{rcccc}
\hline & Total & Primary & Middle & High School \\
\hline Number & 522 & 344 & 115 & 63 \\
\hline Supplements & & & & \\
\hline Vitamin & $15.32 \%$ & $14.82 \%$ & $19.13 \%$ & $11.11 \%$ \\
\hline Fish oil & $9.34 \%$ & $10.50 \%$ & $7.82 \%$ & $6.35 \%$ \\
\hline
\end{tabular}




\begin{tabular}{rcccc}
\hline \multicolumn{1}{c}{ Lutein } & $13.98 \%$ & $13.08 \%$ & $14.78 \%$ & $17.46 \%$ \\
\hline Mydriatic & $97.31 \%$ & $97.09 \%$ & $97.39 \%$ & $98.41 \%$ \\
\hline \multicolumn{1}{c}{ Long-acting } & $28.8 \%$ & $31.39 \%$ & $21.73 \%$ & $23.80 \%$ \\
\hline $\begin{array}{l}\text { Corrective } \\
\text { methods }\end{array}$ & $57.28 \%$ & $49.72 \%$ & $72.17 \%$ & $71.42 \%$ \\
\hline \multicolumn{1}{c}{ Spectacles } & $56.32 \%$ & $48.54 \%$ & $71.30 \%$ & $71.42 \%$ \\
\hline Contact lenses & $3.25 \%$ & $2.48 \%$ & $5.21 \%$ & $4.76 \%$ \\
\hline Orthokeratology & $0.57 \%$ & $0.00 \%$ & $1.73 \%$ & $1.58 \%$ \\
\hline
\end{tabular}

Table 3 lists the perceived causes of myopia of the schoolchildren. According to the extent literature, extensive usage of eyes for reading / studying and TV watching are important behavioural-related causes of myopia $\left[{ }^{18,} 19,20\right]$. Lack of exercise and sleep are also shown to contribute to refractive error [21, 22, 23]. The sampled children in this study reported that lack of exercise was most likely to cause their myopia, followed by extensive hours of reading, and TV watching, with approval rates of 3.80, 3.71, and 3.57, respectively, on the 5-point Likert scale.

Table 3. Perceived Causes of Myopia.

\begin{tabular}{rcccc}
\hline & Total & Primary & Middle & $\begin{array}{c}\text { High } \\
\text { School }\end{array}$ \\
\hline Reading & $3.71(1.18)$ & $3.74(1.21)$ & $3.65(1.10)$ & $3.63(1.15)$ \\
\hline TV & $3.57(1.35)$ & $3.67(1.32)$ & $3.27(1.49)$ & $3.61(1.26)$ \\
\hline Exercise & $3.80(1.20)$ & $3.86(1.17)$ & $3.61(1.27)$ & $3.78(1.14)$ \\
\hline Sleep & $3.45(1.31)$ & $3.36(1.31)$ & $3.48(1.37)$ & $3.85(1.10)$ \\
\hline Genetics & $3.45(1.26)$ & $3.54(1.26)$ & $3.44(1.22)$ & $3.00(1.20)$ \\
\hline Space & $2.89(1.22)$ & $2.93(1.23)$ & $2.94(1.20)$ & $2.56(1.16)$ \\
\hline Injury & $2.24(1.31)$ & $2.25(1.30)$ & $2.14(1.31)$ & $2.38(1.34)$ \\
\hline
\end{tabular}

Numbers in parentheses represent \pm standard deviation.

\section{Multivariate Analyses and Sensitivity Tests}

In order to understand the extent to which each factor contributes to schoolchildren's myopia, multivariate regression analyses were conducted. Absolute values of dioptre 
were employed as the dependent variable. The analysis results, as shown in Table 4, were drawn from four regression estimations with models (1) and (2) using dioptre in level and (3) and (4) in natural logarithm; models (1) and (3) used age in logarithm and (2) and (4) used quadratic forms. The results suggest that older children and those with younger age at onset tended to have a higher degree of myopia. Children or parents with better vision care knowledge tended to have less severity of myopia. The results are significant at the $1 \%$ or $5 \%$ significance level. Children going to private schools and families concerned about their living or activity spaces tended to have milder case of myopia. Use of long-acting mydriatics was positively related to higher dioptres of myopia. One or both parents being myopic was positively related to children's severity of myopia. Intake of food supplements and school academic performance, however, were not significantly related to the severity of myopia.

Table 4. Regression Analysis of Factors that Explain the Variation in Myopia ${ }^{\dagger}$.

\begin{tabular}{lcccc}
\hline & $\mathbf{( 1 )}$ & $\mathbf{( 2 )}$ & $\mathbf{( 3 )}$ & $\mathbf{( 4 )}$ \\
\hline Age & $.84^{* * *}$ & $3.41^{* * *}$ & $.17^{* * *}$ & $.89^{* * *}$ \\
& 3.21 & 5.36 & 2.57 & 5.15 \\
Age $^{2}$ & -0.02 & & 0.00 & \\
& -1.88 & & -1.20 & \\
Onset Age & $-.74^{* * *}$ & $-3.07^{* * *}$ & $-.11^{* * *}$ & $-.69^{* * *}$ \\
& -6.01 & -11.79 & -3.42 & -9.70 \\
Onset Age & $0.01^{*}$ & & 0.00 & \\
& 1.66 & & -0.46 & \\
Height (growth in & 0.04 & 0.06 & 0.02 & $0.02^{*}$ \\
the past year) & & & & \\
& 1.12 & 1.49 & 1.57 & 1.85 \\
Space & -0.11 & -0.11 & $-0.04 *$ & -0.03 \\
& -1.46 & -1.40 & -1.83 & -1.46 \\
Income & 0.21 & 0.24 & 0.00 & 0.00 \\
& 1.11 & 1.26 & -0.07 & 0.02 \\
Mydriatic & $0.34^{*}$ & $.41^{* *}$ & $0.09 *$ & $.12^{* *}$ \\
& 1.77 & 2.11 & 1.70 & 2.21 \\
Private School & $-0.39^{*}$ & $-0.44^{* *}$ & -0.08 & $-0.10^{*}$ \\
Middle school & -1.78 & -1.97 & -1.42 & -1.71 \\
& 0.59 & 0.32 & -0.03 & -0.09 \\
High school & 0.30 & 0.16 & -0.05 & -0.16 \\
\hline & $5.14^{* *}$ & $5.15^{* *}$ & 0.76 & 0.70 \\
\hline
\end{tabular}




\begin{tabular}{|c|c|c|c|c|}
\hline & 2.00 & 2.01 & 1.12 & 1.01 \\
\hline \multirow[t]{2}{*}{ Grade } & -0.07 & -0.07 & $-.03 * *$ & $-0.03 *$ \\
\hline & -1.47 & -1.44 & -2.22 & -1.96 \\
\hline \multirow[t]{2}{*}{ Vitamin } & -0.08 & -0.12 & 0.02 & 0.01 \\
\hline & -0.32 & -0.52 & 0.24 & 0.08 \\
\hline \multirow[t]{2}{*}{ Fish oil } & -0.07 & 0.15 & -0.08 & -0.03 \\
\hline & -0.22 & 0.47 & -0.98 & -0.40 \\
\hline \multirow{2}{*}{$\begin{array}{l}\text { Eye care } \\
\text { knowledge }\end{array}$} & $-0.02 *$ & $-.02 * *$ & $-.01 * *$ & $-.01 * *$ \\
\hline & -1.95 & -2.40 & -2.35 & -2.38 \\
\hline \multirow[t]{2}{*}{ Parental myopia } & 0.14 & 0.22 & $.09 * *$ & $.11 *$ \\
\hline & 0.79 & 1.19 & 2.02 & 2.24 \\
\hline \multicolumn{5}{|c|}{ Elementary Activities (in hours) } \\
\hline \multirow{2}{*}{ Cram School } & 0.05 & 0.06 & 0.02 & 0.02 \\
\hline & 0.84 & 0.97 & 1.43 & 1.56 \\
\hline \multirow[t]{2}{*}{ Electronics } & -0.07 & -0.10 & -0.03 & -0.04 \\
\hline & -0.69 & -0.97 & -1.25 & -1.50 \\
\hline \multirow[t]{2}{*}{ TV } & 0.00 & 0.03 & -0.01 & 0.00 \\
\hline & -0.03 & 0.30 & -0.24 & 0.04 \\
\hline \multirow[t]{2}{*}{ Study } & $-0.23 *$ & -0.23 & $-.07 * *$ & $-.072 * *$ \\
\hline & -1.92 & -1.90 & -2.29 & -2.19 \\
\hline \multirow[t]{2}{*}{ Sleep } & 0.06 & 0.07 & 0.02 & 0.01 \\
\hline & 0.58 & 0.62 & 0.54 & 0.49 \\
\hline \multirow[t]{2}{*}{ Exercise } & 0.01 & 0.01 & 0.00 & 0.00 \\
\hline & 0.29 & 0.29 & 0.42 & 0.43 \\
\hline \multicolumn{5}{|c|}{ Middle School Activities (in hours) } \\
\hline \multirow[t]{2}{*}{ Cram School } & 0.01 & -0.08 & 0.01 & -0.02 \\
\hline & 0.04 & -0.66 & 0.27 & -0.71 \\
\hline \multirow[t]{2}{*}{ Exercise } & -0.07 & -0.08 & $-0.02 *$ & $-0.03 *$ \\
\hline & -1.27 & -1.42 & -1.62 & -1.72 \\
\hline \multirow[t]{2}{*}{ Electronics } & 0.02 & -0.03 & 0.02 & 0.02 \\
\hline & 0.15 & -0.15 & 0.50 & 0.39 \\
\hline \multirow[t]{2}{*}{ TV } & 0.23 & 0.11 & 0.05 & 0.02 \\
\hline & 1.21 & 0.57 & 0.99 & 0.37 \\
\hline \multirow[t]{2}{*}{ Sleep } & -0.14 & -0.01 & -0.01 & 0.01 \\
\hline & -0.65 & -0.07 & -0.22 & 0.25 \\
\hline \multirow[t]{2}{*}{ Study } & $0.37 * *$ & $0.33 *$ & $0.10^{*}$ & $0.10 *$ \\
\hline & 1.90 & 1.65 & 1.86 & 1.74 \\
\hline \multicolumn{5}{|c|}{ High School Activities (in hours) } \\
\hline \multirow[t]{2}{*}{ Cram School } & $-0.34 *$ & $-0.35^{*}$ & -0.08 & -0.07 \\
\hline & -1.67 & -1.68 & -1.45 & -1.20 \\
\hline \multirow[t]{2}{*}{ Exercise } & 0.03 & 0.04 & -0.01 & -0.01 \\
\hline & 0.29 & 0.45 & -0.48 & -0.38 \\
\hline \multirow[t]{2}{*}{ Electronics } & $0.39 *$ & 0.38 & 0.09 & 0.10 \\
\hline & 1.63 & 1.59 & 1.49 & 1.47 \\
\hline TV & $-.48 *$ & $-.55^{*}$ & $-.12 *$ & $-.15^{*}$ \\
\hline & -2.11 & -2.42 & -1.97 & -2.31 \\
\hline Sleep & $-.85 * * *$ & $-.83 * * *$ & $-.16^{* *}$ & $-0.14^{*}$ \\
\hline & -2.89 & -2.82 & -2.10 & -1.77 \\
\hline
\end{tabular}




\begin{tabular}{rcccc}
\hline Study & $.54^{* *}$ & $0.48^{*}$ & $.18^{* * *}$ & $.16^{* *}$ \\
& 2.03 & 1.81 & 2.62 & 2.21 \\
\hline $\mathrm{R} 2$ & 0.49 & 0.43 & 0.45 & 0.38 \\
\hline
\end{tabular}

Myopia is measured in absolute value of dioptre.

${ }^{*}$ Models (1) and (2) have dioptre in level and (3) and (4) have dioptre in natural logarithm. Income is in natural logarithm. Models (1) and (3) are in age logarithm forms and (2) and (4) are in quadratic forms.

$* \mathrm{p}<0.1$

$* * \mathrm{p}<0.05$

$* * * \mathrm{p}<0.01$

In terms of daily activities, time spent in studying / reading did not increase the level of myopia for children in primary school. However, it did significantly aggravate myopia for middle school and high school children. Middle school children who spent more time in exercising had lower levels of myopia. This effect, however, was not significant for those in the primary or high school levels. Usage of electronic devices did not result in a higher degree of myopia for those in primary or middle school. The effect was prominent, though, for high school students. Other activities found beneficial for eyesight included more time spent sleeping and TV watching, which might be considered as time spent in resting and relaxing.

To understand the factors that contribute to the progression of myopia, further regression analyses were performed employing the change in dioptre (in absolute value) in the past year of the sampled children. The results are presented in Table 5. Onset age (in natural logarithms) played the most significant role in myopia progression. Growth in height was also positively related to increase in myopia. Regarding daily activities for elementary schoolchildren, only the length of time spent in cram school was positively associated with myopia progression. For middle school children, exercise and TV watching were significantly beneficial for controlling nearsightedness, whilst usage of electronic devices was harmful. For high school 
students, the only factor shown to slow down the progression of myopia was more hours of sleep.

Table 5. Regression Analysis of Factors that Explain the Progression of Myopia ${ }^{\dagger}$.

\begin{tabular}{|c|c|c|c|c|}
\hline & $(1)^{*}$ & (2) & (3) & (4) \\
\hline \multirow[t]{2}{*}{ Age } & -0.07 & $0.39 *$ & 0.05 & 0.21 \\
\hline & -0.81 & 1.79 & 0.23 & 0.44 \\
\hline \multirow[t]{2}{*}{$\mathrm{Age}^{2}$} & 0.01 & & 0.00 & \\
\hline & 1.35 & & -0.12 & \\
\hline \multirow[t]{2}{*}{ Onset Age } & -0.04 & $-0.26 * * *$ & -0.07 & $-0.32 *$ \\
\hline & -1.02 & -2.95 & -0.70 & -1.65 \\
\hline \multirow[t]{2}{*}{ Onset Age ${ }^{2}$} & 0.00 & & 0.00 & \\
\hline & 0.30 & & 0.40 & \\
\hline \multirow[t]{2}{*}{$\begin{array}{l}\text { Height (growth in } \\
\text { the past year) }\end{array}$} & 0.02 & 0.01 & $0.05 *$ & $0.05^{*}$ \\
\hline & 1.57 & 1.09 & 1.85 & 1.83 \\
\hline \multirow[t]{2}{*}{ space } & 0.02 & 0.02 & -0.01 & 0.01 \\
\hline & 0.59 & 0.90 & -0.12 & 0.14 \\
\hline \multirow[t]{2}{*}{ Income } & 0.04 & 0.04 & -0.06 & -0.06 \\
\hline & 0.59 & 0.56 & -0.38 & -0.43 \\
\hline \multirow[t]{2}{*}{ Mydriatic } & -0.05 & -0.04 & -0.16 & -0.15 \\
\hline & -0.83 & -0.65 & -1.11 & -1.03 \\
\hline \multirow[t]{2}{*}{ Private School } & 0.00 & -0.01 & 0.02 & 0.00 \\
\hline & 0.07 & -0.12 & 0.14 & 0.01 \\
\hline \multirow{2}{*}{ Middle school } & 0.42 & 0.50 & 1.06 & 1.15 \\
\hline & 0.63 & 0.74 & 0.70 & 0.78 \\
\hline \multirow[t]{2}{*}{ High school } & -0.17 & 0.04 & 1.48 & 1.50 \\
\hline & -0.20 & 0.05 & 0.73 & 0.76 \\
\hline \multirow[t]{2}{*}{ Grade } & -0.02 & -0.02 & -0.06 & -0.05 \\
\hline & -1.35 & -1.31 & -1.52 & -1.41 \\
\hline \multirow{2}{*}{ Vitamin } & 0.01 & 0.02 & 0.03 & 0.04 \\
\hline & 0.13 & 0.25 & 0.19 & 0.22 \\
\hline \multirow[t]{2}{*}{ Fish oil } & -0.06 & -0.08 & -0.04 & -0.10 \\
\hline & -0.59 & -0.75 & -0.16 & -0.42 \\
\hline \multicolumn{5}{|l|}{ Eye care } \\
\hline knowledge & $\begin{array}{l}0.00 \\
-0.26\end{array}$ & $\begin{array}{l}0.00 \\
0.06\end{array}$ & $\begin{array}{c}0.00 \\
-0.43\end{array}$ & $\begin{array}{l}0.00 \\
0.00\end{array}$ \\
\hline \multirow[t]{2}{*}{ Parental myopia } & 0.02 & 0.01 & 0.13 & 0.07 \\
\hline & 0.34 & 0.15 & 0.89 & 0.49 \\
\hline \multicolumn{5}{|c|}{ Elementary Activities (in hours) } \\
\hline \multirow[t]{2}{*}{ Cram School } & 0.03 & 0.03 & $0.07 *$ & $0.08^{*}$ \\
\hline & 1.41 & 1.50 & 1.71 & 1.81 \\
\hline \multirow[t]{2}{*}{ Electronics } & 0.03 & 0.02 & -0.04 & -0.03 \\
\hline & 0.74 & 0.61 & -0.52 & -0.40 \\
\hline \multirow[t]{2}{*}{ TV } & 0.05 & 0.05 & 0.03 & 0.01 \\
\hline & 1.32 & 1.14 & 0.30 & 0.15 \\
\hline \multirow[t]{2}{*}{ Study } & -0.06 & -0.06 & -0.04 & -0.05 \\
\hline & -1.37 & -1.44 & -0.49 & -0.60 \\
\hline
\end{tabular}




\begin{tabular}{|c|c|c|c|c|}
\hline Sleep & 0.06 & 0.06 & 0.06 & 0.07 \\
\hline & 1.58 & 1.54 & 0.78 & 0.82 \\
\hline Exercise & 0.02 & 0.02 & 0.03 & 0.03 \\
\hline & 1.38 & 1.55 & 1.26 & 1.25 \\
\hline \multicolumn{5}{|c|}{ Middle School Activities (in hours) } \\
\hline \multirow[t]{2}{*}{ Cram School } & -0.04 & -0.04 & -0.14 & -0.14 \\
\hline & -1.00 & -1.05 & -1.58 & -1.64 \\
\hline \multirow[t]{2}{*}{ Exercise } & -0.02 & -0.03 & $-0.08^{*}$ & $-0.07 *$ \\
\hline & -1.20 & -1.28 & -1.69 & -1.66 \\
\hline \multirow[t]{2}{*}{ Electronics } & $.13 * * *$ & $.14 * * *$ & $.35 * * *$ & $.35 * * *$ \\
\hline & 2.30 & 2.48 & 2.61 & 2.68 \\
\hline \multirow[t]{2}{*}{ TV } & $-.13 * *$ & $-0.13^{*}$ & -0.24 & -0.20 \\
\hline & -2.08 & -1.91 & -1.55 & -1.36 \\
\hline \multirow[t]{2}{*}{ Sleep } & -0.11 & -0.11 & -0.22 & -0.24 \\
\hline & -1.43 & -1.54 & -1.31 & -1.45 \\
\hline \multirow[t]{2}{*}{ Study } & 0.09 & 0.10 & 0.13 & 0.14 \\
\hline & 1.39 & 1.41 & 0.83 & 0.93 \\
\hline \multicolumn{5}{|c|}{ High School Activities (in hours) } \\
\hline \multirow[t]{2}{*}{ Cram School } & 0.09 & 0.10 & 0.15 & 0.15 \\
\hline & 1.33 & 1.39 & 0.94 & 0.93 \\
\hline \multirow[t]{2}{*}{ Exercise } & -0.04 & -0.04 & 0.00 & 0.00 \\
\hline & -1.26 & -1.30 & 0.01 & 0.06 \\
\hline \multirow[t]{2}{*}{ Electronics } & -0.05 & -0.03 & 0.02 & 0.02 \\
\hline & -0.59 & -0.31 & 0.11 & 0.13 \\
\hline \multirow[t]{2}{*}{ TV } & -0.05 & -0.05 & 0.11 & 0.12 \\
\hline & -0.61 & -0.59 & 0.65 & 0.69 \\
\hline \multirow[t]{2}{*}{ Sleep } & -0.04 & -0.04 & $-0.39 *$ & $-0.39 *$ \\
\hline & -0.39 & -0.38 & -1.72 & -1.73 \\
\hline \multirow[t]{2}{*}{ Study } & 0.11 & 0.08 & 0.18 & 0.17 \\
\hline & 1.20 & 0.89 & 0.86 & 0.84 \\
\hline $\mathrm{R} 2$ & 0.13 & 0.12 & 0.11 & 0.11 \\
\hline
\end{tabular}

${ }^{\dagger}$ Myopia is measured in absolute value of dioptre.

*Models (1) and (2) have dioptre in level and (3) and (4) have dioptre in natural logarithm. Income is in natural logarithm. Models (1) and (3) are in age logarithm forms and (2) and (4) are in quadratic forms. Constant is omitted to save space.

$* \mathrm{p}<0.1$

$* * \mathrm{p}<0.05$

$* * * \mathrm{p}<0.01$

The relationships between age of onset of myopia and current myopic status of

schoolchildren in different educational stages are shown in Figure 1. Children with

earlier onset age of myopia had higher current level of myopia. 
Figure 1. Age of Onset of Myopia and Current Dioptre of Schoolchildren.

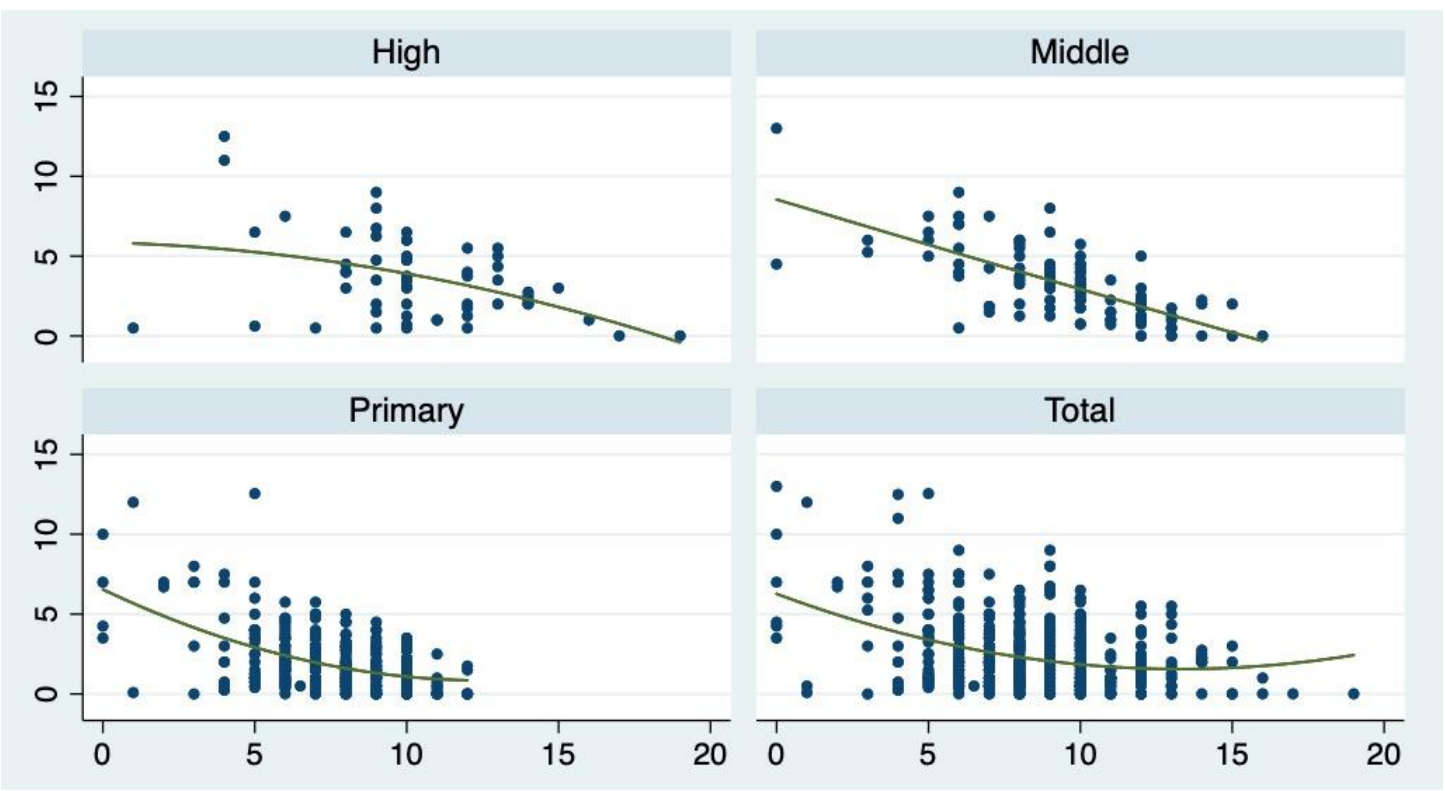

Note: The vertical axis is the level of dioptre and the horizontal axis is the onset age of myopia. Patients in different educational stages are categorized.

Focusing on the myopic progression in the past year, we can also see the similar relationships between the age of onset of myopia and the myopic progression in the past year as shown in Figure 2. Children with earlier onset age of myopia had more myopic progression in the past year.

Figure 2. Age of Onset of Myopia and Dioptre Changes in the Past Year. 


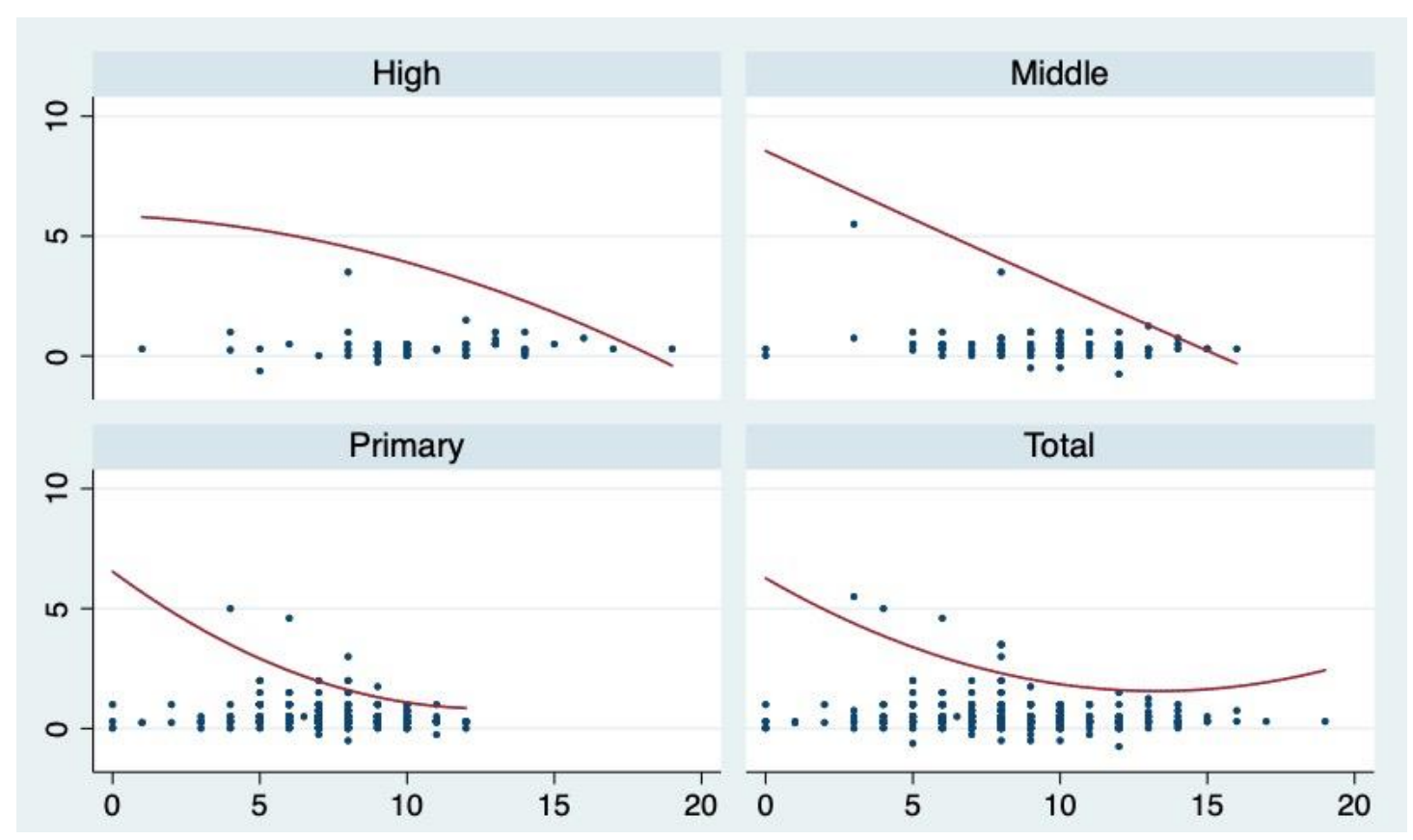

Note: The vertical axis is the level of dioptre and horizontal axis is the onset age of myopia. Patients in different educational stages are categorized.

\section{Discussion}

Myopia has long been a health epidemic issue in many developed countries.

Understanding the risk factors and eye care principles related to myopia are important for promoting both the eyesight and the general health of the population as a whole, since myopia is linked to many serious eye complications. The results of our study are in general consistent with the extent research in terms of genetic factors and the impact of exercise, near work activities, and screen devices usage $\left[{ }^{13,23,24,25}\right]$. Further implications can be drawn from our findings, as follows. First, the intake of food supplement did not significantly impact on schoolchildren's myopia. One may argue that the impact of food supplement can be bi-directional, since patients with more severe myopia may want to use more food supplements. After considering the endogenous nature of regression analysis, the results remain valid. With annual sales of $\$ 567$ million in the food supplement market in Taiwan, of which approximately 
$50.85 \%$ is for eye care $\left[{ }^{26}\right]$, it is noteworthy that food supplements to prevent or control myopia may have little effect. Second, people believe that extensive reading / studying and lack of exercise are most important risk factors for myopia. However, when people are aware of this possibility and concerned that their living condition is not spacious enough, they take precautions to prevent myopia and have better eyesight than those who are not concerned. Third, better eye care knowledge in parents resulted in children with better eyesight. Fourth, the length of time in using electronic devices and hours spent in cram school were positively related to the progression of myopia. The former is especially true for high school students and the latter is especially prominent in primary school children. Lastly, it is important to build up good habits in eye protection for children in elementary schools. Even though high school students are considered to use their eyes more intensively for studying or using electronic devices than younger children, their myopia progression was not as fast as that of younger children, implying that the onset of myopia at an earlier age is especially harmful for one's vision. Therefore, delaying the onset age of myopia may reduce its severity.

\section{Limitations}

Our participants were urban schoolchildren with different levels of myopia. The results may not be applicable to students who live in rural areas with a different lifestyle. In addition, no information on comorbidities or healthcare service utilization related to other diseases was incorporated in the study. Since eye conditions can be related to other health issues, missing this information could be a potential shortcoming in this research. 


\section{Conclusion}

Previous research has extensively discussed the risk factors for myopia and emphasize the significant impact on the severity of myopia and its progression of genetic factors, school achievement, and daily activities such as reading / studying behaviour and exercise. In this study, the findings suggest that near work activities and environmental factors are influential in myopia pathogenesis $\left[{ }^{27}\right]$. The length of time staying in cram school during the primary school years is positively associated with the level of myopia. The effect disappears for middle and high school students, implying that the environment factor is especially important for younger children. Longer time spent in exercise or sleep may result in less myopia progression. Parentor self-knowledge of myopia prevention and self-awareness of being in a confined environment are related to less severity of myopia. The findings suggest that policies that promote eye care education, the awareness of environmental influences on myopia, and outdoor activities are effective measures to protect the eyes of schoolchildren and help them maintain better eyesight throughout their lives. 


\section{Acknowledgements}

The authors thank Taipei Tzu-chi Hospital for assistance with data collection. This

study was supported by a grant from Taipei Tzu Chi Hospital, Buddhist Tzu Chi

Medical Foundation, New Taipei, Taiwan (TCRD-TPE-108-47). The sponsor had no

role in the design or conduct of this research. The authors have no potential conflicts

of interest to disclose. 


\section{References}

1 Pruett RC. Complications associated with posterior staphyloma. Curr Opin Ophthalmol 1998;9:16-22.

2 Saw SM, Gazzard G, Shih-Yen EC, et al. Myopia and associated pathological complications. Ophthalmic Physiol Opt 2005;25:381-91.

3 Saw SM. How blinding is pathological myopia? Br J Ophthalmol 2006;90:525-6.

${ }^{4}$ Hsu WM, Cheng CY, Liu JH, et al. Prevalence and causes of visual impairment in an elderly Chinese population in Taiwan: the Shihpai Eye Study. Ophthalmology 2004;111:62-9.

5 Iwase A, Araie M, Tomidokoro A, et al. Prevalence and causes of low vision and blindness in a Japanese adult population: the Tajimi Study. Ophthalmology 2006;113:1354-62.

${ }^{6} \mathrm{Xu}$ L, Wang Y, Li Y, et al. Causes of blindness and visual impairment in urban and rural areas in Beijing: the Beijing Eye Study. Ophthalmology 2006;113:1134.e1 11. [Crossref] [PubMed]

7 Buch H, Vinding T, La Cour M, et al. Prevalence and causes of visual impairment and blindness among 9980 Scandinavian adults: the Copenhagen City Eye Study. Ophthalmology 2004;111:53-61.

${ }^{8}$ Klaver CC, Wolfs RC, Vingerling JR, et al. Age-specific prevalence and causes of blindness and visual impairment in an older population: the Rotterdam Study. Arch Ophthalmol 1998;116:653-8.

9 Cotter SA, Varma R, Ying-Lai M, et al. Causes of low vision and blindness in adult Latinos: the Los Angeles Latino Eye Study. Ophthalmology 2006;113:1574-82

10 Gifford P, Gifford KL. The future of myopia control contact lenses. Optom Vis Sci 2016;93:336-343.

11 Wu PC, Chang LC, Niu YZ, Chen ML, Liao LL, Chen CT. Myopia prevention in Taiwan. Ann Eye Sci 2018;3:12.

12 Mutti DO, Zadnik K. The utility of three predictors of childhood myopia: a Bayesian analysis. Vision Res 1995; 35:1345-52 Mutti DO, Jones LA, Moeschberger ML, Zadnik K. AC/A ratio, age, and refractive error in children. Invest Ophthalmol Vis Sci 2000a; 41:2469-78.

13 Mutti DO, Mitchell GL, Moeschberger ML, Jones LA, Zadnik K. Parental myopia, near work, school achievement, and children's refractive error. Invest Ophthalmol Vis Sci 2002a; 43:3633-40.

14 Mutti DO, Semina E, Marazita M, Cooper M, Murray JC, Zadnik K. Genetic loci for pathological myopia are not associated with juvenile myopia. Am J Med Genet 2002b; 112:355-60.

15 Lee YY, Lo CT, Sheu SJ, Lin JL. What factors are associated with myopia in young adults? A survey study in Taiwan military conscripts. Invest Ophthalmol Vis Sci. 2013; 54: 1026-1033

16 Congdon NG, Friedman DS, Lietman T. Important causes of visual impairment in the world today. JAMA. 2003; 290: 2057-2060.

17 Shih YF, Chen CH, Chou AC, et al. Effects of different concentrations of atropine on controlling myopia in myopic children. J Ocul Pharmacol Ther 1999;15:85-90.

18 Quek TP, Chua CG, Chong CS, Chong JH, Hey HW, Lee J, Lim YF, Saw SM. Prevalence of refractive errors in teenage high school students in Singapore. Ophthalmic Physiol Opt 2004; 24:47-55

19 Mutti DO, Zadnik K. The utility of three predictors of childhood myopia: a Bayesian analysis. Vision Res 1995; 35:1345-52 
${ }^{20}$ Curtin BJ, Karlin DB. Axial length measurements and fundus changes of the myopic eye. Am J Ophthalmol 1971; 71:42-53.

${ }^{21}$ Mutti DO, Jones LA, Moeschberger ML, Zadnik K. AC/A ratio, age, and refractive error in children. Invest Ophthalmol Vis Sci 2000a; 41:2469-78.

22 Mutti DO, Mitchell GL, Moeschberger ML, Jones LA, Zadnik K. Parental myopia, near work, school achievement, and children's refractive error. Invest Ophthalmol Vis Sci 2002a; 43:3633-40.

23 Rose KA, Morgan IG, Ip J, Kifley A, Huynh S Et Al. Outdoor activity reduces the prevalence of myopia in children. Ophthalmol; $2008 ; 115: 1279-1285$

${ }^{24}$ Huang HM, Chang DS, Wu PC. The Association between Near Work Activities and Myopia in Children-A Systematic Review and Meta-Analysis. PLoS One. 2015;10(10):e0140419. Published 2015 Oct 20. doi:10.1371/journal.pone.0140419

25 Ritvija Dixit, Manisha Jindal et al: Excessive Usage of Illuminated Screen a Risk Factor for Myopia in Adolescent Population: International Journal of current Medical and Applied sciences; 2016, 10(3),173-176 (15) (PDF) Excessive Usage of Illuminated Screen a Risk Factor for Myopia in Adolescent Population.

Available

from: https://www.researchgate.net/publication/321152875_Excessive_Usage_of_I lluminated_Screen_a_Risk_Factor_for_Myopia_in_Adolescent_Population [accessed May 03 20 $\overline{19}$ ].

26 China Grain Products Research \& Development Institute. 2016 annual report on Value added and promotion of foold supplement industry. Available online at https://www.functionalfood.org.tw/pld/survey2015.pdf

27 Saw SM, Wu HM, Seet B, et al. Academic achievement, close up work parameters, and myopia in Singapore military conscripts. Br J Ophthalmol. 2001;85(7):855860. doi:10.1136/bjo.85.7.855 